\title{
CORRELATION BETWEEN BITING FORCE AND MUSCLE ACTIVITY ACCORDING TO IMPLANT POSITION IN LOWER CLASS I KENNEDY PARTIAL DENTURE
}

\author{
Noha H Nawar* and Nora M Sheta**
}

\begin{abstract}
Purpose: The placement of dental implants in a distal RPD extension provided more stable and reliable occlusion. The target of this trial was to investigate the degree of correlation between the maximum biting force and surface electromyography of masseter fibers and anterior fibers of temporalis in two different implant positions in lower Kennedy class I
\end{abstract}

Material and methods : Fourteen patients having lower Kennedy class I with the first premolar as the last abutment and completely dentulous maxilla were randomly divided into two equal groups to receive implant supported partial overdenture. Each group received posterior bilateral two implants in the second molar area in the first group, while the group 2 one in the second premolar area. Right and left Maximum biting force was measured for both groups using I loadstar sensor and masseter and anterior temporalis muscle activity were evaluated with Surface Electromyography

Result : The data revealed that group I had significant positive correlation between maximum biting force and the masseter and anterior temporalis muscles activity in both the right and the left side with $\mathrm{r}$ value $(1,0.79,0.89$ and 0.75$)$ respectively on the other hand the group II showed no significant positive correlation with $\mathrm{r}(0.04,0.01 .-0.04$ and -0.11$)$ respectively

Conclusion : Within the limitation of this clinical trial, it was concluded that there were better muscle coordination between the two largest muscles of mastication (masseter and temporalis) and the produced biting force as a product due to installation of posterior implant in the lower second molar area.

KEY WORD: Lower Kennedy class I, Implant supported partial overdenture, biting force, muscles activity

\section{INTRODUCTION}

Distal extension partially edentulous patients face several problems, which should be managed wisely to preserve the surrounding tissues and to maintain stability of the stomatognathic system $^{(1)}$. In designing distal extension removable

* Associate Professor of Removable Prosthodontics, Faculty of Dentistry, Ain Shams University.

** Lecturer of Removable Prosthodontics, Faculty of Dental Medicine, Cairo University 
partial dentures (RPDs), it is important to restore masticatory function as well as to preserve abutment teeth and residual ridge. The influence of occlusal factors on masticatory performance and the stability of the denture base should be considered. (2)

Recently, the implant-supported removable partial dentures had proven to be a more dependable alternative to conventional removable partial dentures. However the implant's insertion is limited by anatomical limitations. In this situation, a minor number of shorter implants can be placed to stabilize the RPD in vertical direction, provide comfort and increase patient masticatory efficacy. ${ }^{(3,4)}$ The literature proved that implant supported removable partial denture improves the prosthetic biomechanics, resulting in greater patient satisfaction. Keltjens et al ${ }^{(5)}$ stated that the insertion of implants in a distal RPD extension provided more stable and reliable occlusion Brudvik ${ }^{(6)}$ proved that molar and canine areas are the most appropriate positions for implants placement. However implant in the molar region can provide better biomechanical configuration.

Biting force is an important variable to investigate oral function related to occlusal factor. The natural dentition fixed, removable and Implants prosthesis may affect the biting force. In addition orthognatic surgery, temporo- mandibular disorders and neuromuscular changes should be considered. Muscle force and the number of functional teeth are determinant factors in masticatory efficiency. The measurement of the maximum bite force is an attempt to quantify the force that mandible elevator muscles can make. ${ }^{(7)}$

The bite force measurements can be made directly by using a suitable transducer that has been placed between a pair of teeth. This direct method of force assessment appears to be an easy way of assessing the submaximal force. An alternative method is indirect evaluation of the bite force by employing the other physiologic variables known to be functionally related to the force production. ${ }^{(8)}$ Surface Electromyography of the elevator muscles of the mandible can be measured from the cutaneous projection of the muscular belly. In this way, obtained data give an idea for the bite force. The results of some investigations showed a linear relationship between electromyography activity potentials and direct bite force measurements, especially at a submaximal level. ${ }^{(9)}$

Increasing of the biting force is considered as success indicators of the prosthesis that this means improvement of the oral functions. It was found that the biting force magnitudes of mandibular implant-supported overdentures subjects have been $60 \%-200 \%$ higher than those of subjects with conventional complete dentures. ${ }^{(10-12)}$

Evaluation of muscle activity can be done with Surface Electromyography. It is a non-invasive technique where surface electrodes are placed on the skin overlying a muscle or group of muscles. It is widely used to record compound muscle action potentials. ${ }^{(13)}$

However due to increasing utilizing the implants as means to solve the free end saddle problems, the purpose of the current study is to investigate the degree of correlation between the maximum biting force and surface electromyography of master fibers and anterior fibers of temporalis in two different implant position in lower Kennedy class I

\section{MATERIAL AND METHODS}

\section{Participants}

A total of 14 participants were chosen from the Prosthodontic Out-Patient Clinic of Faculty of Dentistry Ain-Shams University. The patients enrolled in the current study had age ranged between 50-60 and complained of partial edentulism having lower Kennedy class I with the first premolar as the last abutment and completely dentulous maxilla. All the patients were investigated to ensure being free from any systemic diseases which could affect 
bone metabolism, as well as they were thoroughly examined to exclude any muscle discoordination or habitual habits which could affect measuring the biting force. Cone beam computed tomography were done to ensure presence of sufficient bone width and length to receive posterior implant of $10 \mathrm{~mm}$ length and $3.5 \mathrm{~mm}$ diameter in the predetermined sites. A computed printed surgical stent were constructed for all patients which were designed to be bone supported.

\section{Patient grouping}

The patients were then randomly assigned using random number generator and checker into (www. psychicscience.org/random.aspx) into two equal groups.

Group I: Seven patients received posterior bilateral two implants in the second molar area

Group II: seven patients received posterior bilateral two implants in the second premolar area.

\section{Surgical and prosthetic procedure}

All the patients undergone guided surgical procedures and implant installation using bone supported computerized surgical guide after flap elevation (fig. 1) in the predesigned sites.

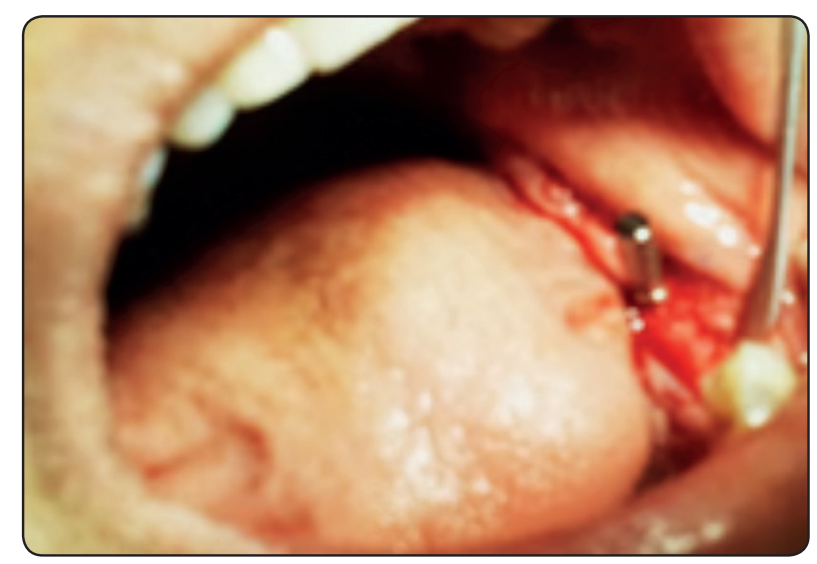

Fig. (1) Surgical placment of implant in second molar region
Delayed loading protocol were followed, installation of ball abutment were done after 4 month then, the prosthetic procedure were performed using the conventional steps in constructing implant retained partial overdenture.(fig 2)

The design of the framework was unified in both groups consisting of bilateral RPI clasps on the first premolars, canine rests as indirect retainer and lingual bar as major connector. Picking up of the female part of the ball was done using self-cure acrylic resin.

\section{Biting force assessment}

Maximum biting force was measured for both groups using I loadstar sensor (loadstar sensors.453 Riverdale Drive, Mountain view, CA94043). The sensors was prepared and calibrated, the patients were seated upright to ensure vertical direction of applied force. The dome shaped top of the sensors was placed in the occlusal embrasure between the upper premolar and the first molar on one side of the mouth (fig 3) as this area allows the patient to exert maximum controlled force, ${ }^{(14)}$ while on the contralateral side a cotton rolls was placed, then the patient was asked to exert maximum biting force. This method was applied to the right and left side of the patients.

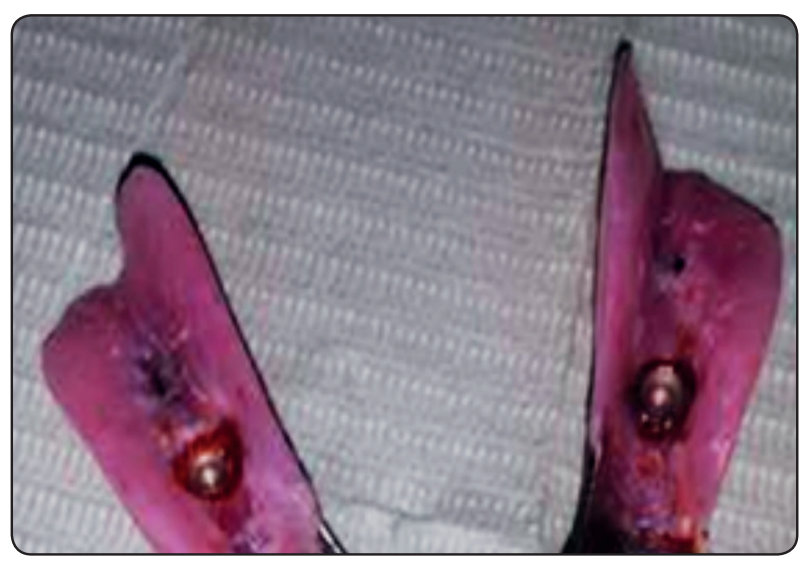

Fig. (2) Removable implant retained partial overdenture by ball attachment in second premolar region 


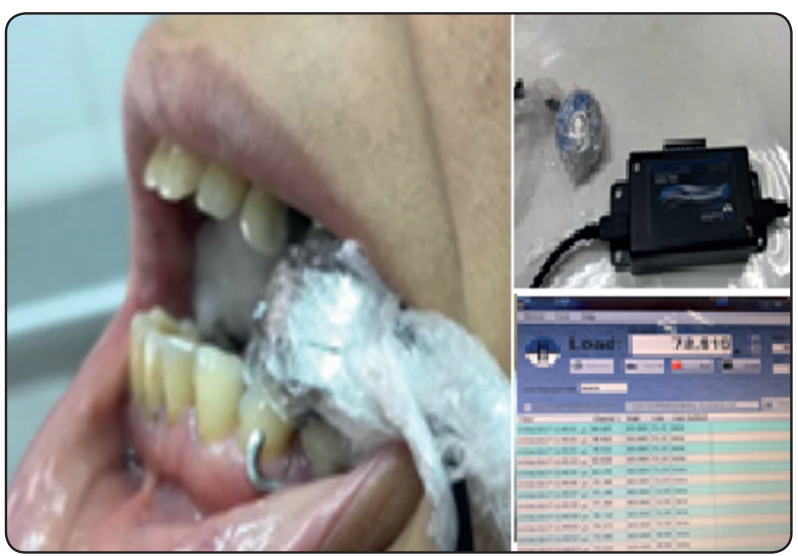

Fig. (3) Measurment of biting force using I loadstar sensor

\section{Recording electromyogram of masseter and tem- poralis}

The two muscles studied (masseter and anterior fibers of temporalis) were first located. The masseter muscle was located by asking the patient to clench and marking of the muscle was done one $\mathrm{cm}$. behind the palpated anterior border in the area of the greatest lateral distention parallel to the main direction of the fibers. The temporalis muscle was located by asking the patient to open and close with palpation just in front of the anterior border of the hair line in the area of the greatest lateral distention.

The sites of electrodes placement were rubbed with abrasive gel and cleansed with a cotton pellet moistened with alcohol before placement of electrodes. A conductive gel was applied to the inner side of the electrode (between the electrode and skin) before fixation in the planned position.

Active surface electrode was positioned in this location of the maximum bulge of the muscle and another reference electrode was placed $2-3 \mathrm{~cm}$. beside it along the main direction of the muscle fibers. The electrodes were fixed to the patient's face with adhesive strips to avoid bias due to movements. The ground surface electrode was located on the patient's forehead. The muscle activity of each patient was recorded while exerting maximum biting force in both the right and the left site. (Fig 4)

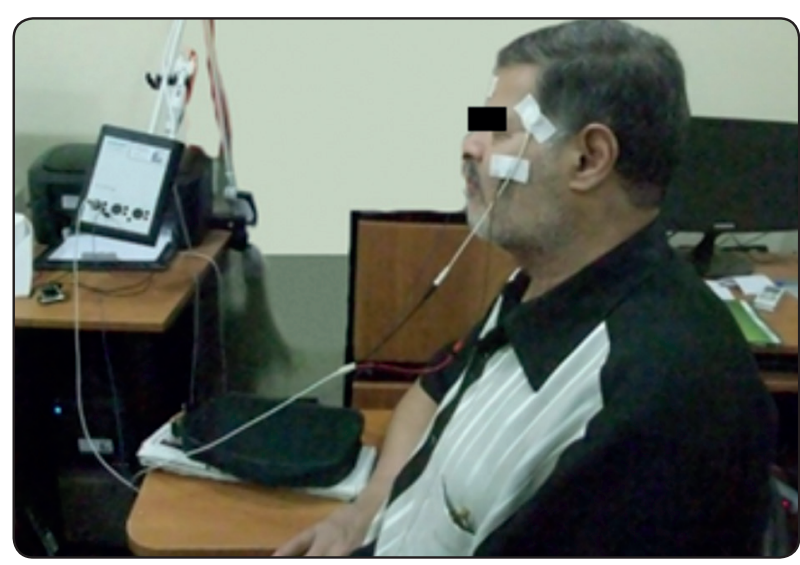

Fig. (4) Electromyogram measurment

\section{Statistical Analysis}

The data were collected and then analyzed using SPSS software Probability values $\leq 0.05$ to indicate significant relationships between variables. All calculations were made with the SPSS software package (version 13.1: SPSS Inc). Descriptive data were tabulated, and the tested variables were not normally distributed as Kolmogorov-Smirnova and Shapiro-Wilk tests was used to assess data normality. Spearman's correlation test was used to correlate different variables (the maximum biting force and the muscles activity). Maximum biting force and muscles activity values in the two groups were tested using Man n-Whitney $U$ test. All the data in the Tables and text were described as median and interquartile range (IQR)

\section{RESULT}

The group II reported a higher maximum biting was statistically significant $(p<0.002)$ in both the right and the left side as confirmed in table 1. On the other hand, group I reported a higher muscles activity in both the right and the left side. The value was statistically significant $(p<0.002)$ in right and left masseter muscles. The right and left temporalis muscle was statistically significant with $(\mathrm{p}<0.015)$ and $(\mathrm{p}<0.041)$ respectively as confirmed in table 2 
As shown in table 3 and figure 5 there was in the right and the left side while there was positive correlation and statistically significance positive correlation but not statistically significance between biting force in group I and muscle activity between biting force and muscle activity in group II.

TABLE (1) The median, interquartile range and $\mathrm{P}$ values for comparing right and left maximum biting force in newton $(\mathrm{N})$ in both groups

\begin{tabular}{|c|c|c|c|c|}
\hline Variable & groups & Median & IQR & p value \\
\hline \multirow{2}{*}{ Right maximum biting force } & I & 129.3 & 2.2 & \multirow{2}{*}{$0.002^{*}$} \\
\cline { 2 - 4 } & II & 148.2 & 5.3 & \multirow{2}{*}{$0.002^{*}$} \\
\hline \multirow{2}{*}{ Left maximum biting force } & I & 110.5 & 17.6 & 11.1 \\
\cline { 2 - 4 }
\end{tabular}

TABLE (2) The median, interquartile range and $\mathrm{P}$ values for comparing right and left muscle activity in micro volts $(\mathrm{Mv})$

\begin{tabular}{|c|c|c|c|c|}
\hline Variables & groups & Median & IQR & $\mathrm{p}$ value \\
\hline \multirow{2}{*}{ Right masseter muscle activity } & I & 62.2 & 3.9 & \multirow{2}{*}{$0.002^{*}$} \\
\hline & II & 31.5 & 9.8 & \\
\hline \multirow{2}{*}{ Left masseter muscle activity } & I & 60.2 & 7.7 & \multirow{2}{*}{$0.002^{*}$} \\
\hline & II & 31.2 & 8 & \\
\hline \multirow{2}{*}{ Right temporalis muscle activity } & I & 47 & 7.2 & \multirow{2}{*}{$0.015^{*}$} \\
\hline & II & 40.3 & 10.1 & \\
\hline \multirow{2}{*}{ Left temporalis muscle activity } & I & 47.2 & 9 & \multirow{2}{*}{$0.041^{*}$} \\
\hline & II & 35.2 & 9 & \\
\hline
\end{tabular}

TABLE (3) Correlation between right and left maximum biting force and muscles activity in both groups.

\begin{tabular}{|l|l|l|l|}
\hline & group & r & p value \\
\hline $\begin{array}{l}\text { Right maximum biting force and Right } \\
\text { masseter muscle activity }\end{array}$ & I & 1 & $0.01^{*}$ \\
\cline { 2 - 4 } & II & 0.04 & 0.94 \\
\hline $\begin{array}{l}\text { Right maximum biting force and Right } \\
\text { temporalis muscle activity }\end{array}$ & I & 0.79 & $0.04^{*}$ \\
\cline { 2 - 4 } $\begin{array}{l}\text { Left maximum biting force and left } \\
\text { masseter muscle activity }\end{array}$ & I & 0.11 & 0.82 \\
\cline { 2 - 4 } Left maximum biting force and left & I & 0.89 & $0.01^{*}$ \\
\cline { 2 - 4 } temporalis muscle activity & II & -0.04 & 0.94 \\
\hline
\end{tabular}




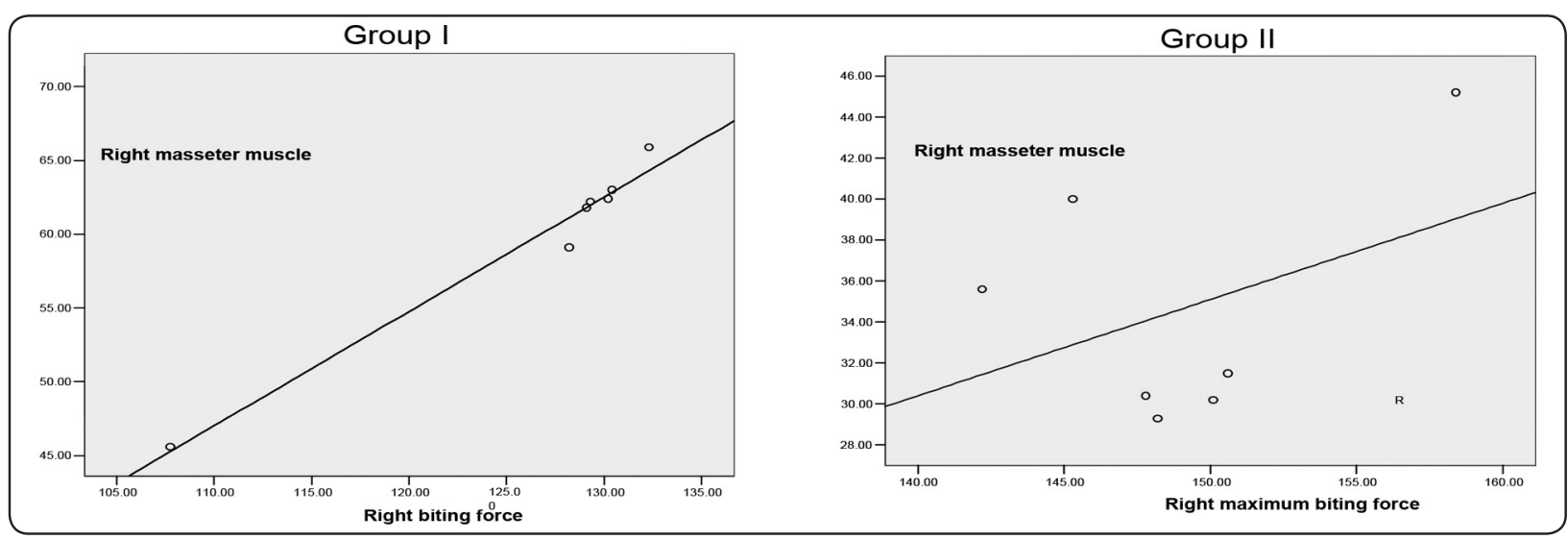

Fig. (5) Correlation between right maximum biting force and right masseter muscle in both groups

\section{DISCUSSION}

Partial or complete prosthetic replacement of missing teeth is associated with decreased chewing efficiency and consequently decreased patient satisfaction. ${ }^{(11)}$ Several factors affect the efficiency of the masticatory such as the positioning of posterior teeth in the dental arch, bite force, malocclusion, degree and site of occlusal contacts. Among all factors, the positioning of posterior teeth and the bite force are the most important factors affecting the efficiency of the masticatory $\operatorname{system}^{\cdot(15)}$

Various methods have been used to assess the efficiency of the masticatory system, including the measurement of bite force and chewing function, for this reason the current study involved measuring the biting force ${ }^{(16,17}$ Lassila et al ${ }^{(17)}$ concluded that high MBF plays major role in patient's satisfaction. The introduction of osseointegrated implants allowed replacing missing teeth with higher success rate and also allowed resolving the difficulties with the usage of conventional removable partial dentures such as decreased bite force as it was proved that the bite force decreased in edentulous patients between $20 \%$ to $50 \%$ compared with the natural dentition. ${ }^{(18-20)}$ Van Kampen et al ${ }^{(12)}$ observed a significant increase in masticatory function after rehabilitation with implant supported overdenture .The current study had proven that installation of implants in free end saddle increased the biting force in group II significantly than in group I which could be attributed to that it is considered the center of occlusal forces as described by the shortened arch theory. Many recent studies revealed that when implant placed in the premolar region in distal extension cases it received more stress and higher biting force by comparing to implant placed in the molar region ${ }^{(21-23)}$ which explains the result observed of group II as shown in table 1

Biting force by itself is not adequate to evaluate muscle strength because bite force is strongly influenced by the amount of voluntary effort, which may be less than maximal effort. True muscle strength depends upon muscle size, muscle recruitment, and the length of the muscle moment arms. Therefore, the relationship between EMG and bite force, as well as the mechanical advantage of the jaw muscles, should be determined when ass ssing jaw muscle strength. ${ }^{(24)}$ The purpose of this study was to correlate the maximum bite force and EMG activity of the jaw abductor muscles (masseter and temporalis).

The left as well as the right side were assessed independently in this study to take into consideration the preferred chewing side of each patient which known as the "habitual chewing side syndrome"(25). Biting force varies in different regions of the oral cavity. ${ }^{(26)}$ Several researches concluded that the more posterior biting force is ,the greater the contribution 
of anterior fibers of temporalis assessing the action of masseter which runs in consistent with the results of this study which showed increasing in the activity of temporalis in group I than in group II. $(8,27,28)$, this besides the positive significance correlation in group I which suggest that patients were capable of exerting efficient biting force in coordination with efficient muscle activity, in addition greater bite force can be tolerated better in posterior areas . ${ }^{(27)}$ In accordance to Grossman et al. who recommended the second molar position for installation of posterior implant in distal extension cases ${ }^{(29)}$

\section{CONCLUSION}

Within the limitation of this clinical trial, it was concluded that there were better muscle coordination between the two largest muscle of mastication (masseter and temporalis) and the produced biting force as a product to those muscle activity due to installation of posterior implant in the lower second molar area.

\section{REFERENCES}

1- Itoh, H., Caputo, A.A., Wylie, R.: Effects of periodontal support and fixed splinting on load transfer by removable partial dentures. J. Prosthet. Dent. .1998 . 79:465-471

2- Lammie GA, Laird WRE. Osborne \& Lammie's partial dentures. 5th ed. Oxford: Blackwell, 1986:295-6.

3- Rocha, E.P., Luersen, M.A., Pellizzer, and E.P.: Distalextension removable partial denture associated with an osseointegrated implant. Study by the finite element method. J. Dent. Res. 2003, 82: B-254

4- Verri, F.R., Pellizzer, E.P., Rocha, E.P. \& Pereira, J.A.: Influence of Length and Diameter of Implants Associated With Distal Extension Removable Partial Dentures; Imp Dent 16: 2007 275-280.

5- Keltjens HM, Kayser AF, Hertel R, Battistuzzi PG.: Distal extension removable partial dentures supported by implants and residual teeth: considerations and case reports. Int J Oral Maxillofac Implants. 1993;8:208-213

6- Brudvik JS. Advanced removable partial dentures. Chicago: Quintessence, 1999.
7- Van der Bilt, A., Tekamp, A., Van der Glas, H. and Abbink, J. Bite force and electromyography during maximum unilateral and bilateral clenching. European Journal of Oral Sciences.2008 116, 217-222

8- Ferrario VF, Sforza C, Zanotti G, Tartagilia GM. Maximal bite force in healthy young adults as predicted by surface electromyography. J Dent. 2004; 32:451-457.

9- Castroflorio T, Bracco P, Farina D. Surface electromyography in the assessment of jaw elevator muscles. J Oral Rehabil. 2008; 35:638-645.

10- Haraldson T, Jemt T, Stalblad P, Lekholm U. Oral function in subjects with overdentures supported by osseointegrated implants. Scand J Dent Res. 1988; 96:235-242.

11- Fontijn-Tekamp FA, Slagter AP, van't Hof MA, Geertman ME, Kalk W. Bite forces with mandibular implant-retained overdentures. J Dent Res. 1998; 77:1832-1839.

12- Van Kampen FMC, van der Bilt A, Cune MS, Bosman F.: The influence of various attachment types in mandibular implant-retained overdentures on maximum bite force and EMG. J Dent Res. 2002; 81:170-173.

13- Gea Drost, Dick F. Stegeman, Baziel G.M. van Engelen, Machiel J. Zwarts.: Clinical applications of high density surface EMG: A systematic review. Journal of Electromyography and Kinesiology. 2006; 16:586-602.

14- Geckili O, Bilhan H, Mumcu E, Tuncer N: The Influence of Maximum Bite Force on Patient Satisfaction and Quality of Life of Patients Wearing Mandibular Implant Overdentures, Journal of Oral Implantology2012,271-277: XXXVIII (3)

15- Hatch JP, Shinkai RS, Sakai S, Rugh JD, Paunovich ED. Determinants of masticatory performance in dentate adults. Arch Oral Biol. 2001;46:641-648

16- Fontijn-Tekamp FA, Slagter AP, Van Der Bilt A: Biting and chewing in overdentures, full dentures, and natural dentitions.J Dent Res. 2000; 79: 1519-1524.

17- Lassila V, Holmlund I, Koivumaa KK.: Bite force and its correlations in different denture types. Acta Odontol Scand.1985; 43:127-132.

18- Van Waas MA, Jonkman RE, Kalk W, Van 't Hof MA, Plooij J, Van Os JH. Differences two years after tooth extraction in mandibular bone reduction in patients treated with immediate overdentures or with immediate complete dentures. J Dent Res.1993;72: 1001-1004. 
19- Bakke M, Holm B, Gotfredsen K. Masticatory function and patient satisfaction with implant-supported mandibular overdentures:a prospective 5-year study. Int J Prosthodont. 2002; 15: 575-581.

20- Van Rensburg BGJ. Oral Biology. $1^{\text {st }}$ ed. Berlin: Quintessence Publishing; 1995.

21- Memari Y, Geramy A, Fayaz A, Rezvani Habib Abadi S, Mansouri Y. Influence of implant position on stress distribution in implant-assisted distal extension removable partial dentures: A 3D finite element analysis. J Dent (Tehran). 2014; 11(5):523-530.

22- Matsudate Y, Yoda N, Nanba M, Ogawa T, Sasaki K. Load distribution on abutment tooth, implant and residual ridge with distal-extension implant-supported removable partial denture. J Prosthodont Res. 2016. Epublication ahead of print.

23- Oh WS, Oh TJ, Park JM. Impact of implant-support on mandibular free-end base removable partial denture: Theoretical study. Clin Oral Implants Res. 2016;27(2):e87-90.

24- Kiliaridis S, Kjellberg H, Wenneberg B, Engström C The relationship between maximal bite force, bite force endurance, and facial morphology during growth. Acta Odontologica Scandinavica. 1993 51: 323-331

25- Santana-Mora U, López-Cedrún J, Mora MJ, Otero XL, Santana- Penín U. Temporomandibular disorders: the habitual chewing side syndrome. PLoS One. 2013;8(4):e59980.

26- Ferrario VF, Sforza C., Serrao G., Dellavia C., Tartagilia GM. : Single tooth bite forces in healthy young adults .j. oral Rehabil.2004:31,18-22

27- Tortopidis D, Lyons MF, Baxendle RH, Gilmour WH. The variability of bite force measurements between sessions, in different positions within the dental arch. J. Oral rehabil. 1998:25:,681-686

28- Braun S, Freudenthaler JW, Honigle K.A study of maximum bite force during growth and development.Angle Orthod.1996:66;261-264

29- Grossmann Y, Nissan J, Levin L. Clinical effectiveness of implant-supported removable partial dentures: A review of the literature and retrospective case evaluation. J Oral Maxillofac Surg. 2009;67(9):1941-1946. 